(2) Open Access Full Text Article

\title{
In vitro human skin permeation of endoxifen: potential for local transdermal therapy for primary prevention and carcinoma in situ of the breast
}

\author{
Oukseub Lee' \\ David Ivancic' \\ Robert T Chatterton J ${ }^{2}$ \\ Alfred W Rademaker ${ }^{3}$ \\ Seema A Khan' \\ 'Department of Surgery, ${ }^{2}$ Department \\ of Obstetrics/Gynecology, \\ ${ }^{3}$ Department of Preventive Medicine, \\ Northwestern University Feinberg \\ School of Medicine, Chicago, IL, USA
}

Correspondence: Seema A Khan

Northwestern University Feinberg School

of Medicine, 303 E Superior St Lurie

4-I I I, Chicago, IL 606 I I, USA

$\mathrm{Tel}+\mathrm{I} 3 \mid 25034236$

Fax +I 3125032555

Email skhan@nmh.org
This article was published in the following Dove Press journal:

Breast Cancer:Targets and Therapy

I 3 July 201 I

Number of times this article has been viewed

Purpose: Oral tamoxifen, a triphenylethylene (TPE), is useful for breast cancer prevention, but its adverse effects limit acceptance by women. Tamoxifen efficacy is related to its major metabolites 4-hydroxytamoxifen (4-OHT) and $N$-desmethyl-4-hydroxytamoxifen (endoxifen [ENX]). Transdermal delivery of these to the breast may avert the toxicity of oral tamoxifen while maintaining efficacy. We evaluated the relative efficiency of skin permeation of 4-OHT and ENX in vitro, and tested oleic acid (OA) as a permeation-enhancer.

Methods: 4-OHT, ENX, and estradiol (E2) $\left(0.2 \mathrm{mg} / \mathrm{mL}\right.$ of $\left.0.5 \mu \mathrm{Ci}{ }^{3} \mathrm{H} / \mathrm{mg}\right)$ were dissolved in $60 \%$ ethanol-phosphate buffer, $\pm \mathrm{OA}(0.1 \%-5 \%)$. Permeation through EpiDerm ${ }^{\mathrm{TM}}$ (Matek Corp, Ashland, MA) and split-thickness human skin was calculated based on the amount of the agents recovered from the receiver fluid and skin using liquid scintillation counting over 24 hours.

Results: In the EpiDerm model, the absorption of 4-OHT and ENX was 10\%-11\%; total penetration (TP) was $26 \%-29 \%$ at 24 hours and was decreased by OA. In normal human skin, the absorption of $4-\mathrm{OHT}$ and ENX was $0.3 \%$; TP was $2 \%-4 \%$ at 24 hours. The addition of $1 \%$ OA improved the permeation of ENX significantly more than that of 4-OHT $(P<0.004)$; further titration of $\mathrm{OA}$ at $0.25 \%-0.5 \%$ further improved the permeation of ENX to a level similar to that of estradiol.

Conclusion: The addition of OA to ENX results in a favorable rapid delivery equivalent to that of estradiol, a widely used transdermal hormone. The transdermal delivery of ENX to the breast should be further developed in preclinical and clinical studies.

Keywords: endoxifen, breast cancer prevention, human skin, transdermal, oleic acid

\section{Introduction}

For more than three decades, oral administration of tamoxifen (TAM), a triphenylethylene (TPE), has been a standard component of the treatment of estrogen receptor- $\alpha$ $(E R \alpha)$-positive breast cancer, ${ }^{1}$ and, more recently, has been used for prevention, for both pre- and postmenopausal women. ${ }^{2}$ However, TAM is a prodrug that requires conversion by the phase I drug metabolizing enzymes cytochrome P450 (CYP2D6 and CYP3A4/5) to its major antiestrogenic metabolites, 4-hydroxytamoxifen (4-OHT), and $N$-desmethyl-4-hydroxytamoxifen (endoxifen [ENX]), which have equivalent affinity for ER $\alpha$ that is $100 \times>$ TAM. Recent reports suggest that ENX is the dominant metabolite responsible for the therapeutic effect of TAM because of its greater abundance (10× higher than 4-OHT in serum) and its ability to cause proteosomic degradation of $\mathrm{ER} \alpha .^{3-5}$ 
The effectiveness of TAM may be compromised in about $33 \%$ of women because of enzyme polymorphisms, which result in decreased availability of ENX. In addition, long-term systemic exposure to TAM is associated with hot flashes, night sweats, and menstrual irregularity, as well as the more serious risks of thromboembolism and endometrial cancer. ${ }^{6}$ Thus, the systemic delivery of TAM is problematic both from the perspective of efficacy through inefficient metabolism and toxicity through high systemic exposure. However, in women with ductal carcinoma in situ (DCIS) and those at high risk for breast cancer, effective concentrations are required only in breast tissue; systemic exposure is redundant, and side effects related to it may be largely avoided by transdermal delivery of active TAM metabolites through breast skin, as suggested by Mauvais-Jarvis and others. ${ }^{7-9}$ Promising results have been reported from a presurgical study of postmenopausal women with estrogen receptor (ER)-positive breast cancer. The topical application of 4-OHT gel to the breast skin resulted in inhibition of tumor cell proliferation to the same degree as that seen with the standard dose of oral TAM (20 mg/day) but with much lower plasma levels, 2\%-11\% of those achieved with oral TAM. ${ }^{9}$ In the present study, the in vitro skin permeation of 4-OHT and ENX was evaluated, first using a reconstituted human epidermal skin model, and then normal human skin. Oleic acid (OA) was investigated as a permeation enhancer with the objective of increasing uptake of ENX to that of estradiol (E2), a well-established transdermal agent.

\section{Materials and methods Reagents}

TAM, 4-OHT, E2, absolute ethanol, polyoxyethylene 20-oleyl ether (POE[20]), and OA were purchased from Sigma-Aldrich Corp (St Louis, MO), and ENX was obtained from Toronto Research Chemicals Inc (Toronto, Canada). $\left[\mathrm{N}\right.$-methyl- $\left.{ }^{3} \mathrm{H}\right]$ tamoxifen $\left({ }^{3} \mathrm{H}\right.$-tamoxifen) and $\mathrm{Z}-4-$ hydroxy $\left[N\right.$-methyl $\left.-{ }^{3} \mathrm{H}\right] \operatorname{tamoxifen}\left({ }^{3} \mathrm{H}-4-\mathrm{OHT}\right),(72 \mathrm{Ci} / \mathrm{mmol})$, were obtained from Amersham Biosciences (Piscataway, NJ). CYP2D6 was purchased from BD Biosciences (San Jose, CA). The in vitro human-reconstituted epidermis skin model (EpiDerm ${ }^{\mathrm{TM}}$ skin model EPI-200) and permeation devices (EPI-100-FIX) were obtained from MatTek Corp (Ashland, MA). Franz diffusion cells (\#4G-01-00-07-05) were purchased from PermeGear Inc (Hellertown, PA).

\section{Preparation of ${ }^{3} \mathrm{H}$-endoxifen}

Twenty microcuries of ${ }^{3} \mathrm{H}-4-\mathrm{OHT}$ were incubated in $0.5 \mathrm{~mL}$ of $70 \mathrm{mM}$ phosphate buffer (PB) containing $10 \mu \mathrm{M}$
$\mathrm{Mg}^{2+}, \mathrm{pH} 7.4$, with $0.5 \mathrm{nmol}$ CYP2D6 for 30 minutes at $23^{\circ} \mathrm{C}$. The product was extracted into ethyl ether and was chromatographed on a silica gel thin layer. TAM, 4-OHT, $N$-desmethyltamoxifen, and ENX in this system had $\mathrm{R}_{\mathrm{F}}$ values of $0.60,0.29,0.25$, and 0.06 , respectively. Rechromatography in a second solvent system (benzene:methanol, 1:1) gave $\mathrm{R}_{\mathrm{F}}$ values of 0.51 and 0.25 for ${ }^{3} \mathrm{H}-4-\mathrm{OHT}$ and ${ }^{3} \mathrm{H}-\mathrm{ENX}$, respectively. The products were eluted into methanol and stored at $4{ }^{\circ} \mathrm{C}$. The yield of ${ }^{3} \mathrm{H}-\mathrm{ENX}$ was $>50 \%$. The specific activity of the product was $36 \mathrm{Ci} / \mathrm{mmol}$.

\section{Skin preparations}

The EpiDerm was incubated for 1 hour at $37^{\circ} \mathrm{C}$ with $5 \% \mathrm{CO}_{2}$ prior to dosing. Each of the EpiDerm batches was used within 3 days of delivery. The acquisition of anonymous human skin samples from the operating room was approved by the Institutional Review Board of Northwestern University. The subcutaneous fat from fresh mastectomy and abdominoplasty specimens was removed and the full-thickness skin was immobilized to obtain split-thickness skin (STS) using a surgical blade (George Tiemann and Co, Hauppauge, NY) or an electric dermatome (Robins instrument Inc, Chatham, $\mathrm{NJ})$. The thickness of STS samples was measured with an electronic digital micrometer (Tresna Instruments Co, Guilin, China) as $367 \pm 0.039$ microns.

\section{Skin imaging}

The EpiDerm and STS samples were cut into $3 \mathrm{~mm} \times 10 \mathrm{~mm}$ pieces, placed horizontally in a Cryomold ${ }^{\circledR}$ (Tissue-Tek $^{\circledR}$; Sakura Finetek USA, Torrance, CA), embedded in a tissue freezing medium (OCT ${ }^{\mathrm{TM}}$ Compound; Tissue-Tek), frozen in the microtome/cryostat chamber, sectioned at 7 microns, and stained with Mayer's hematoxylin and eosin. Images were taken with a $20 \times$ objective using a Nikon Eclipse (Tokyo, Japan) optical microscope with a 10 micron bar superimposed on the skin images.

\section{Skin cell viability}

Ethanol toxicity to the skin was determined using the 3-(4, 5-Dimethylthiazol-2-yl)-2, 5-diphenyltetrazolium bromide (MTT) toxicology kit (MTT-100, MatTek) by measuring epidermal cell viability of the EpiDerm. A PB ( $2 \mathrm{mM} \mathrm{KH}_{2} \mathrm{PO}_{4}$, $4 \mathrm{mM} \mathrm{Na}_{2} \mathrm{HPO}_{4}, \mathrm{pH} 7.0$ ) was used as a negative control and $70 \%(\mathrm{v} / \mathrm{v})$ ethanol-PB was the test material. $0.4 \mathrm{~mL}$ of each solution was loaded in the donor chamber of the MatTek permeation device (MPD) (EPI-100-FIX) and $5 \mathrm{~mL}$ of Dulbecco's modified Eagle's medium (DMEM)-based assay medium (EPI-100-ASY) was added in each receiver well. 
Skin samples were incubated at $37^{\circ} \mathrm{C}$ with $5 \% \mathrm{CO}_{2}$. After 6 and 24 hours, skin samples were processed by the MTT assay, following the manufacturer's protocol.

\section{Diffusion studies}

\section{Permeation of TPEs using the MPD}

TPE solutions $\left(0.2 \mathrm{mg} / \mathrm{mL}\right.$ of $0.5 \mu \mathrm{Ci}{ }^{3} \mathrm{H}$-TPEs $\left./ \mathrm{mg}\right)$ were prepared in the control vehicle, $60 \%(\mathrm{v} / \mathrm{v})$ ethanol-PB. To evaluate OA effect on permeation of TPEs, the control vehicle was supplemented with $1 \%-5 \%(\mathrm{v} / \mathrm{v}) \mathrm{OA}$. The receiver chamber contained $5 \mathrm{~mL}$ of phosphate-buffered saline (PBS) with stirring at $37^{\circ} \mathrm{C}$. Skin samples were placed in the MPD with a skin exposure area of $0.256 \mathrm{~cm}^{2}$. A drug solution of $0.2 \mathrm{~mL}$ was loaded into the donor chamber (final dose was $312.6 \mu \mathrm{g} / \mathrm{cm}^{2}$ for EpiDerm and $156.3 \mu \mathrm{g} / \mathrm{cm}^{2}$ for human STS). General procedures for the permeation study followed the manufacturer's protocol. After 6 and 24 hours, receiver fluid was collected, the solution remaining in the donor chamber was removed, and the exposed skin and donor chamber were washed twice with $0.4 \mathrm{~mL}$ of PBS and cleaned with a cotton swab and removed from the permeation device. The amount of ${ }^{3} \mathrm{H}$-TPEs from the washes of the donor chamber, the donor and receiver fluids, and the skin samples was determined by liquid scintillation counting (Beckman Coulter LS6500, Fullerton, CA). For each receiver fluid, $1 \mathrm{~mL}$ aliquots in triplicate were placed in $20 \mathrm{~mL}$ liquid scintillation glass vials, and $10 \mathrm{~mL}$ of Ecolite $(+)^{\mathrm{TM}}(\mathrm{MP}$ Biomedicals, Solon, $\mathrm{OH}$ ) liquid scintillation fluid was added. Skin samples were cut into small pieces with surgical scissors and homogenized using an ultrasonic processor (Cole Parmer, Vernon Hills, IL); the ${ }^{3} \mathrm{H}$-TPEs were extracted three times into methanol; the solvent was evaporated and resuspended in $0.5 \mathrm{~mL}$ methanol and $10 \mathrm{~mL}$ of Ecolite $(+)$ liquid scintillation fluid. ${ }^{3} \mathrm{H}$-TPEs from the donor chamber were measured as follows: ${ }^{3} \mathrm{H}$-TPEs from the cotton swabs were extracted into $1 \mathrm{~mL}$ of methanol three times, then this was added together with the remaining donor solution and washes; the solvent was evaporated and the residue was dissolved in $0.5 \mathrm{~mL}$ methanol and $10 \mathrm{~mL}$ of Ecolite (+) liquid scintillation fluid. Total recovery of ${ }^{3} \mathrm{H}$-TPEs was greater than $95 \%$.

\section{Permeation of ENX using Franz diffusion cells}

ENX and estradiol (E2) $\left(0.2 \mathrm{mg} / \mathrm{mL}\right.$ of $\left.0.5 \mu \mathrm{Ci}{ }^{3} \mathrm{H} / \mathrm{mg}\right)$, were prepared in the control vehicle, $60 \%(\mathrm{v} / \mathrm{v})$ ethanol-PB. OA $(0.1 \%-1 \%)$ was added to the control vehicle, to test its permeation-enhancing effect on ENX. Static Franz diffusion cells (skin exposure area of $0.38 \mathrm{~cm}^{2}$ and receiver chamber volume of $5 \mathrm{~mL}$ ) were used for the permeation experiments. PBS was supplemented with 4\% (w/v) POE(20) to overcome the possible artificial dermal retention of lipophilic compounds. ${ }^{10} 0.1 \mathrm{~mL}$ of drug solution was loaded into the donor chamber (final dose was $78.9 \mu \mathrm{g} / \mathrm{cm}^{2}$ ). Samples of $0.25 \mathrm{~mL}$ were collected at the predetermined intervals over 24 hours. After 24 hours of sampling, the exposed skin area was washed as described, and the epidermis was separated from the dermis by forceps. All other procedures were the same as described previously.

\section{Data and statistical analysis}

Permeation parameters of TPEs using the MPD were expressed as the mean and standard error of the mean (SEM) of the percent of the applied dose from replicate experiments. Absorption is defined as the amount $\left(\mu \mathrm{g} / \mathrm{cm}^{2}\right)$ of TPEs reaching the receiver fluid. The total penetration (TP) was defined as the sum of the absorption and skin contents of TPEs at the predetermined time points. For Franz diffusion cell experiments, the permeation profiles of ENX and E2 were analyzed by plotting the absorption $\left(\mu \mathrm{g} / \mathrm{cm}^{2}\right)$ of the compound as function of time (h). The permeation rate (or flux) at steady state $\left(\mu \mathrm{g} / \mathrm{cm}^{2} / \mathrm{h}\right)$ was calculated from the slope of the linear portion of the permeation curve over 24 hours. The lag time was determined by extrapolating the linear portion of the curve to the $\mathrm{X}$-axis. Permeation parameters of ENX and E2 were expressed as the mean and SEM. The Kruskal-Wallis and Wilcoxon rank sum tests were used for comparisons across the compounds and between OA conditions, with Bonferroni corrections for significance testing as detailed in the Results. Statistical analyses were done using the SAS statistical software (SAS OnlineDoc ${ }^{\circledR}$ 9.2, SAS Institute Inc, Cary, NC).

\section{Results \\ Stratum corneum thickness and ethanol skin toxicity}

The stratum corneum (SC) of EpiDerm was thinner than normal human skin (Figure 1). The skin toxicity of $70 \%(\mathrm{v} / \mathrm{v})$ ethanol-PB was evaluated in the EpiDerm by the MTT assay. Epidermal cells of EpiDerm treated with PB remained highly viable (100\%), whereas $37 \%$ and $44 \%$ of epidermal cells died when treated with $70 \%$ ethanol-PB for 6 and 24 hours, respectively (Figure 2).

\section{Permeation of TPEs across EpiDerm}

The permeation parameters of the TPEs (TAM, 4-OHT, and ENX) across the EpiDerm were investigated with the addition 


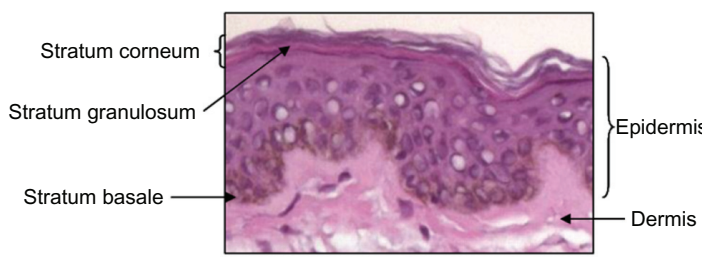

EpiDermis ${ }^{\mathrm{TM}}$ skin model

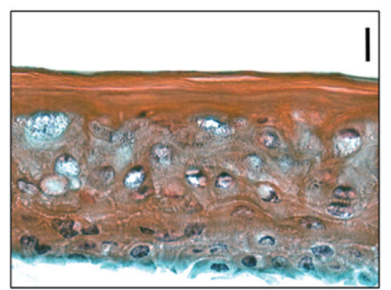

Epidermis of normal human skin

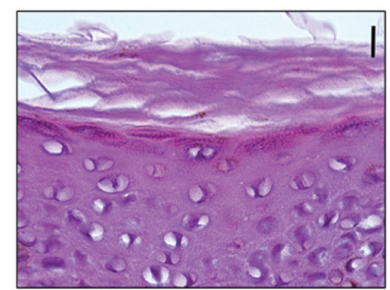

Figure I Skin images of EpiDerm ${ }^{\mathrm{TM}}$ and human STS. Top panel depicts the composition of skin layers. In the lower panel skin images of the EpiDerm (left) and the epidermis of human STS (right) are compared at the same magnification (20x) with a 10 micron bar, showing that SC of human skin is twice as thick as the SC of the EpiDerm.

Abbreviations: SC, stratum corneum; STS, split-thickness skin.

of $1 \% \mathrm{OA}$ and are summarized in Table 1 . In the control vehicle the absorption of TPEs (approximately $1 \%$ of each TPE) was essentially equivalent at 6 hours $(P=0.21)$ but increased at 24 hours, in the order of 4-OHT $>$ ENX $>$ TAM (Kruskal-Wallis $P=0.005$, among all TPEs). For the total penetration (TP) of TPEs we found that the TP of TAM and 4-OHT was similar, but the TP of ENX was significantly

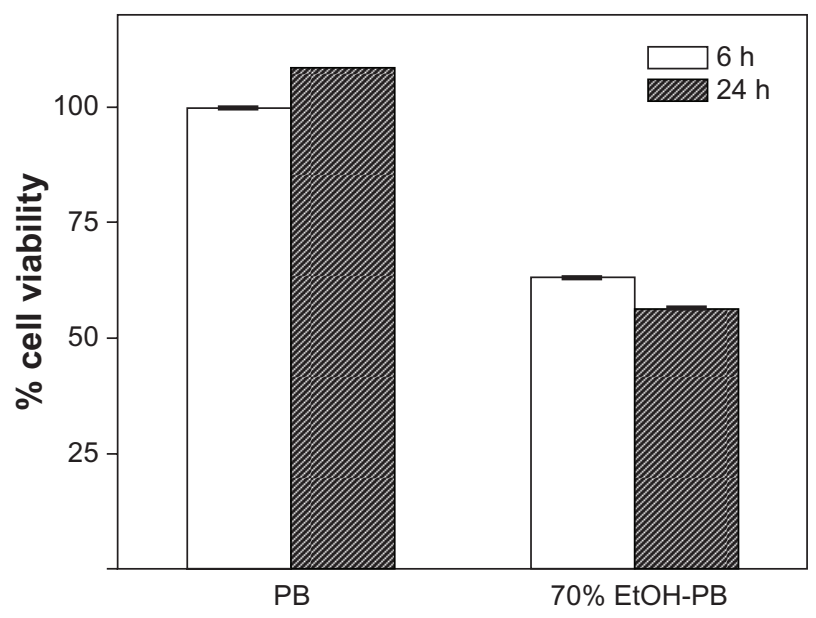

Figure 2 Assessment of ethanol skin toxicity. Toxicity of 70\% (v/v) ethanol-PB was evaluated in the EpiDerm ${ }^{\mathrm{TM}}$ by the MTT assay. $0.1 \mathrm{~mL}$ of PB and $70 \%$ ethanol-PB were loaded on the EpiDerm and MTT assay was performed after 6 and $24 \mathrm{~h}$ incubation at $37^{\circ} \mathrm{C}$. The fraction of epidermal cells remaining highly viable after $24 \mathrm{~h}$ at $37^{\circ} \mathrm{C}$ was measured as the Abs of formazan at $570 \mathrm{~nm}$, subtracting out a background reading for all samples at $650 \mathrm{~nm}$ with UV-visible spectrometer. Percent cell viability was determined at each of the dose concentrations using the following formula: \% viability $=100 \times\left(\left[\mathrm{Abs}_{570}-\mathrm{Abs}_{650}\right]\right.$ of sample $) /\left(\left[\mathrm{Abs}_{570}-\mathrm{Abs}_{650}\right]\right.$ of a negative control $)$ Negative control was PB and all data were normalized using data of PB at $6 \mathrm{~h}$, and reported in mean $\pm S D$.

Abbreviations: Abs, absorbance; EtOH-PB, ethanol-PB; MTT, 3-(4, 5-Dimethylthiazol2-yl)-2, 5-diphenyltetrazolium bromide; PB, phosphate buffer; SD, standard deviation. lower than that of TAM and 4-OHT ( $P=0.006$ for both) at 6 hours. At 24 hours, the total permeation of all TPEs was similar, ranging from $25 \%-29 \%$.

On addition of $1 \% \mathrm{OA}$ into the control vehicle, a uniform and significant decrease in the absorption of TAM, 4-OHT and of ENX over 24 hours was found. The largest reduction was in the TP of TAM (approximate $80 \%$ reduction, $P=0.0008)$. The exception to this adverse trend was a transient increase in the absorption of ENX at 6 hours, in contrast to TAM and 4-OHT, which decreased significantly at 6 hours.

\section{Permeation of TPEs across human skin samples}

Next, we examined the absorption and TP of 4-OHT and ENX across normal human STS, comparing three concentrations of OA $(1,2.5$, and $5 \%)$ to the control vehicle over 24 hours (Table 2). In the control vehicle, the absorption of 4-OHT and ENX were equivalent, but the TP of ENX was approximately half that of 4-OHT $(P=0.002)$. On addition of $1 \%-5 \%$ OA to the control vehicle, both the absorption and the TP of 4-OHT and ENX increased (Kruskal-Wallis $P<0.0001$, for all comparisons). The addition of $1 \%$ OA enhanced the absorption of 4-OHT and ENX by approximately $3 \times$ and $18 \times$, and the TP of these agents by $3 \times$ and $18 \times$, respectively, compared with vehicle controls. The addition of $1 \% \mathrm{OA}$ improved the TP of ENX $1.4 \times$ higher than that of 4-OHT $(P=0.004)$. At higher concentrations of OA $(2.5 \%-5 \%)$ the absorption of $4-\mathrm{OHT}$ and ENX did not further improve; rather, the absorption of ENX decreased when compared with $1 \%$ OA ( $1 \%$ vs $2.5 \%$ OA: $P=0.002,1 \%$ vs $5 \%$ OA: $P=0.0013)$.

\section{Permeation of ENX at lower concentrations of $\mathrm{OA}$}

Having established that 1\% OA enhanced permeation of ENX to a greater extent than 4-OHT in human skin, we explored the effect of lower concentrations of OA $(0.1 \%-1 \%)$ on permeation of ENX using Franz diffusion cells over 24 hours (Figure 3A). The permeation parameters (lag time, flux, absorption, skin content, and TP) of ENX were compared with that of E2, since the transdermal delivery of this hormonal agent is well established (Figures 3 and 4).

In the control vehicle, the lag time of ENX and E2 was similar, the flux of ENX was $<$ E2 (Figures $3 \mathrm{~B}$ and $3 \mathrm{C})$, and the absorption of ENX was $50 \%$ than that of E2 $(P=0.045)$ (Figure 3D). In contrast, the total skin content of ENX was $1.8 \times$ higher than that of E2 $(P=0.045)$. This increase was attributable to the epidermal content of ENX, 
Table I Detrimental effect of OA on permeation of TPEs across EpiDerm ${ }^{\mathrm{TM}}$

\begin{tabular}{|c|c|c|c|c|c|c|c|}
\hline \multicolumn{8}{|c|}{ Percentage of applied dose $\left(3 \mid 2.6 \mu \mathrm{g} / \mathrm{cm}^{2}\right)$, mean \pm SEM $^{a}$} \\
\hline TPEs & OA & Absorption & $P^{b}$ & Skin & $P^{\mathrm{b}}$ & Total penetration & $P^{b}$ \\
\hline \multicolumn{8}{|l|}{$6 \mathrm{~h}$} \\
\hline \multirow[t]{2}{*}{ TAM } & - & $0.8 \pm 0.04$ & 0.011 & $11.0 \pm 0.78$ & 0.0008 & $11.9 \pm 0.78$ & 0.0008 \\
\hline & $1 \%$ & $0.7 \pm 0.04$ & & $2.0 \pm 0.35$ & & $2.6 \pm 0.35$ & \\
\hline \multirow[t]{2}{*}{$4-\mathrm{OHT}$} & - & $1.0 \pm 0.07$ & 0.0006 & $8.8 \pm 0.53$ & 0.0008 & $9.8 \pm 0.60$ & 0.0008 \\
\hline & $1 \%$ & $0.3 \pm 0.04$ & & $4.9 \pm 0.28$ & & $5.2 \pm 0.28$ & \\
\hline \multirow[t]{2}{*}{ ENX } & - & $0.8 \pm 0.07$ & 0.006 & $6.0 \pm 0.78$ & 0.027 & $6.8 \pm 0.85$ & 0.29 \\
\hline & $1 \%$ & $1.5 \pm 0.18$ & & $4.4 \pm 0.35$ & & $5.9 \pm 0.49$ & \\
\hline \multicolumn{8}{|l|}{$24 \mathrm{~h}$} \\
\hline \multirow[t]{2}{*}{ TAM } & - & $4.6 \pm 0.67$ & 0.0007 & $21.3 \pm 1.98$ & 0.012 & $25.9 \pm 2.58$ & 0.0008 \\
\hline & $1 \%$ & $1.4 \pm 0.04$ & & $2.4 \pm 0.39$ & & $3.8 \pm 0.39$ & \\
\hline \multirow[t]{2}{*}{ 4-OHT } & - & $10.9 \pm 1.66$ & $0.00 \mathrm{I}$ & $17.5 \pm 0.64$ & 0.012 & $28.4 \pm 1.94$ & 0.0012 \\
\hline & $1 \%$ & $0.7 \pm 0.04$ & & $7.6 \pm 0.49$ & & $8.3 \pm 0.49$ & \\
\hline \multirow[t]{2}{*}{ ENX } & - & $9.9 \pm 1.03$ & 0.006 & $16.2 \pm 1.10$ & 0.0008 & $26.0 \pm 1.77$ & 0.001 \\
\hline & $1 \%$ & $5.3 \pm 0.88$ & & $6.4 \pm 0.64$ & & $11.7 \pm 1.38$ & \\
\hline
\end{tabular}

Notes: ${ }^{\text {TT }}$ The results are represented as the percentage of applied dose of TPEs from receiver fluid and skin as well as total skin penetration at the predetermined time points ( 6 and 24 hours), values are the mean \pm SEM of observations, with eight observations at each time-point; ball the significant $P$-values are represented in bold, with the Bonferroni-corrected threshold for significance being $P<0.017$.

Abbreviations: 4-OHT, 4-hydroxytamoxifen; ENX, endoxifen (N-desmethyl-4-hydroxytamoxifen); OA, oleic acid; TAM, tamoxifen; TPEs, triphenylethylenes.

which was $4 \times$ higher than that of E2 $(P=0.006)$, while the dermal content of two compounds was similar (Figure 4A). Finally, the TP of ENX was slightly higher $(1.5 \times)$ than that of E2, but the difference was not significant $(P=0.17)$ (Figure 4B).

Next, we evaluated the effect of lower concentrations of OA $(0.1 \%-1 \%)$ on the permeation parameters of ENX. The addition of $0.1 \%$ OA to the control vehicle showed nonsignificant permeation-enhancing effects on the lag time and the flux of ENX in comparison with that in the control vehicle. On addition of $0.25 \%$ and $0.5 \% \mathrm{OA}$, lag time of ENX was shorter ( $P=0.0062$ for both), the flux was significantly enhanced by $2.6-2.8 \times(P<0.05$ for both $)$, and the absorption was increased by $3.2 \times$ and $3.9 \times$, respectively, in comparison with that of ENX in the control vehicle. At the concentration of $1 \% \mathrm{OA}$, we observed that there was no further improvement in the permeation parameters of ENX (Figure 3D). Thus, the flux and the absorption of ENX was lower than that of E2 in the control vehicle, but the addition of $0.25 \%-0.5 \% \mathrm{OA}$ enhanced the flux of ENX equivalent to that of E2 and increased the absorption of ENX superior to that of E2 $(P<0.05)$ (Figures 3C and 3D).

For the skin content, the partitioning of ENX into skin layers was improved by $0.1 \%-1 \%$ OA. These improvements were proportional to the concentration of OA added to the control vehicle, and mainly driven by epidermal rather than dermal content of ENX (Figure 4A). At a concentration of 1\% OA the total skin content of ENX was improved by $1.7 \times$ in comparison with that in the control vehicle $(P=0.045)$
(Figure 4A). This was $3.4 \times$ higher than that of E2 in the control vehicle $(P=0.01)$.

Finally, we observed that the TP of ENX was in the range of $15.7 \%-20.9 \%\left(12.4-16.5 \mu \mathrm{g} / \mathrm{cm}^{2}\right)$ in the presence of $0.1 \%-1 \%$ OA (Figure $4 \mathrm{~B}$ ), so that, with a $1 \%$ concentration of OA, the TP of ENX was $1.7 \times$ higher than in the control vehicle $(P=0.029)$, and $2.4 \times$ higher than that of E2 in the control vehicle (Figure 4B).

\section{Discussion}

Transdermal delivery has long been recognized as an effective form of systemic therapy, with distinct pharmacokinetic and related advantages, but, due to the effectiveness of the barrier function of the stratum corneum, only a small number of drugs have been successfully formulated for this purpose. Existing data on transdermal permeation of 4-OHT suggest that the relatively small and lipophilic nature of this molecule renders it suitable for transdermal formulation. ${ }^{7,8}$ A study using an alcoholic gel formulation of 4-OHT suggests that, when applied to the skin of the breast of postmenopausal women with ER-positive breast cancer, sufficient breast tissue concentrations are achieved for an antiproliferative effect on tumor cells of equal magnitude to that seen with standard doses of oral TAM. ${ }^{9}$ Other studies using the same gel for the treatment of mastalgia show a benefit 4-OHT gel at a concentration of $4 \mathrm{mg} /$ day. ${ }^{11}$ The authors are using the same formulation of 4-OHT in a multicenter presurgical study in DCIS patients (NCT00952731), with the primary endpoint of decreased cell proliferation. 


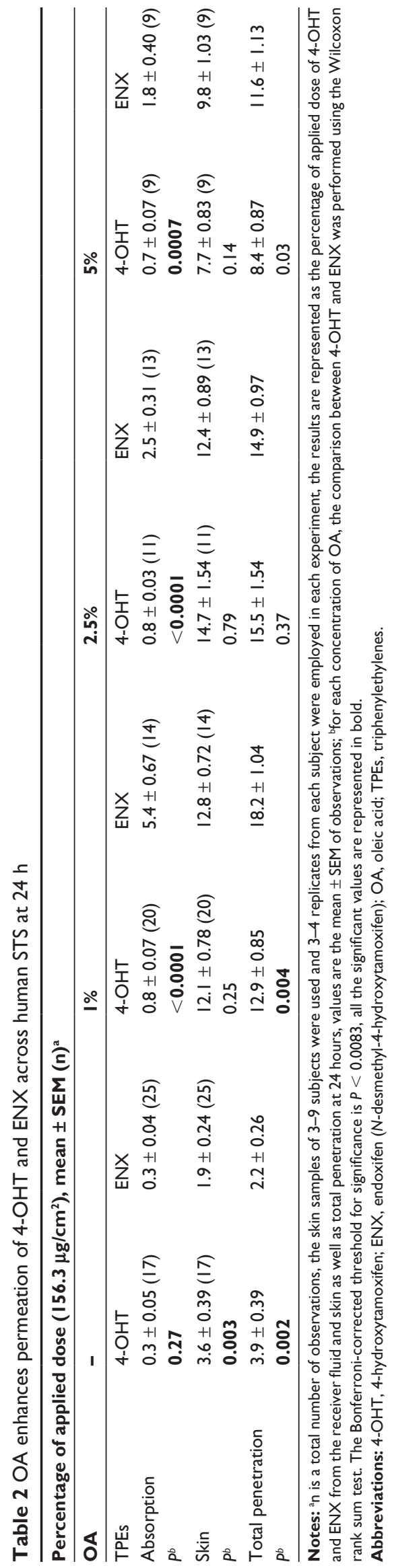

The authors have investigated the relative permeation of 4-OHT and ENX because the binding affinities of 4-OHT and ENX are both $25 \times$ greater for ER $\alpha$ and $56 \times$ greater for ER $\beta$ than that of TAM. ${ }^{12,13}$ ENX has been reported to have an advantage over 4-OHT in that it causes proteosomic degradation of ER $\alpha$ and may have more selective antiestrogenic effects. ${ }^{5}$ Therefore, ENX is expected to give better therapeutic efficacy than 4-OHT, but its specific toxicity profile is currently unknown. If ENX shares even some of the toxicity of the parent drug and its percutaneous absorption in humans is equivalent to (or better) than that of 4-OHT, it would be an excellent candidate for transdermal delivery. Additionally, the chemical structure of ENX would render it more promising for transdermal application because it is more amenable to conjugation to nanoparticles for controlled release. For this reason, the authors have investigated the relative in vitro percutaneous absorption of ENX in comparison with those of 4-OHT and TAM.

It was found that the total penetration of ENX into human skin was not as efficient as that of 4-OHT in the control vehicle, but the addition of $1 \%$ OA greatly improved both absorption and TP of ENX over 24 hours. Although significant increases in these parameters were also seen for 4-OHT, the increase in ENX permeation was larger and brings ENX permeation into a range that is very compatible with transdermal therapy. OA is a well-known permeation enhancer that has been employed to increase absorption of TPEs in the $60 \%(\mathrm{v} / \mathrm{v})$ ethanol-PB vehicle. ${ }^{14}$ Several researchers have observed a permeation-enhancing effect with OA in ethanol-water systems across hairless rodent skin. ${ }^{15-17}$ In the present study, an ethanol-based vehicle was necessary to solubilize TPEs and ethanol also has the advantage of being a widely used skin permeation enhancer used in topical drug-delivery systems for estradiol, progesterone, fentanyl, and other drugs. It is not clear why ENX benefited more from the addition of OA than 4-OHT, but this may be related to a difference in their structure. ENX is smaller and more polar than 4-OHT because one methyl group at a tertiary amine is replaced with a hydrogen, resulting in a secondary amine that is more hydrophilic than the tertiary amine of 4-OHT. Because OA appears to make the stratum corneum fluidic ${ }^{18,19}$ and ethanol gives a continuous driving force, ${ }^{14,20}$ ENX may move faster through the skin than 4-OHT. The amine group of ENX may have a favorable balance of hydrophilic and hydrophobic properties to deal with the stratum corneum, which would allow ENX to traverse the stratum corneum more easily. The results here 

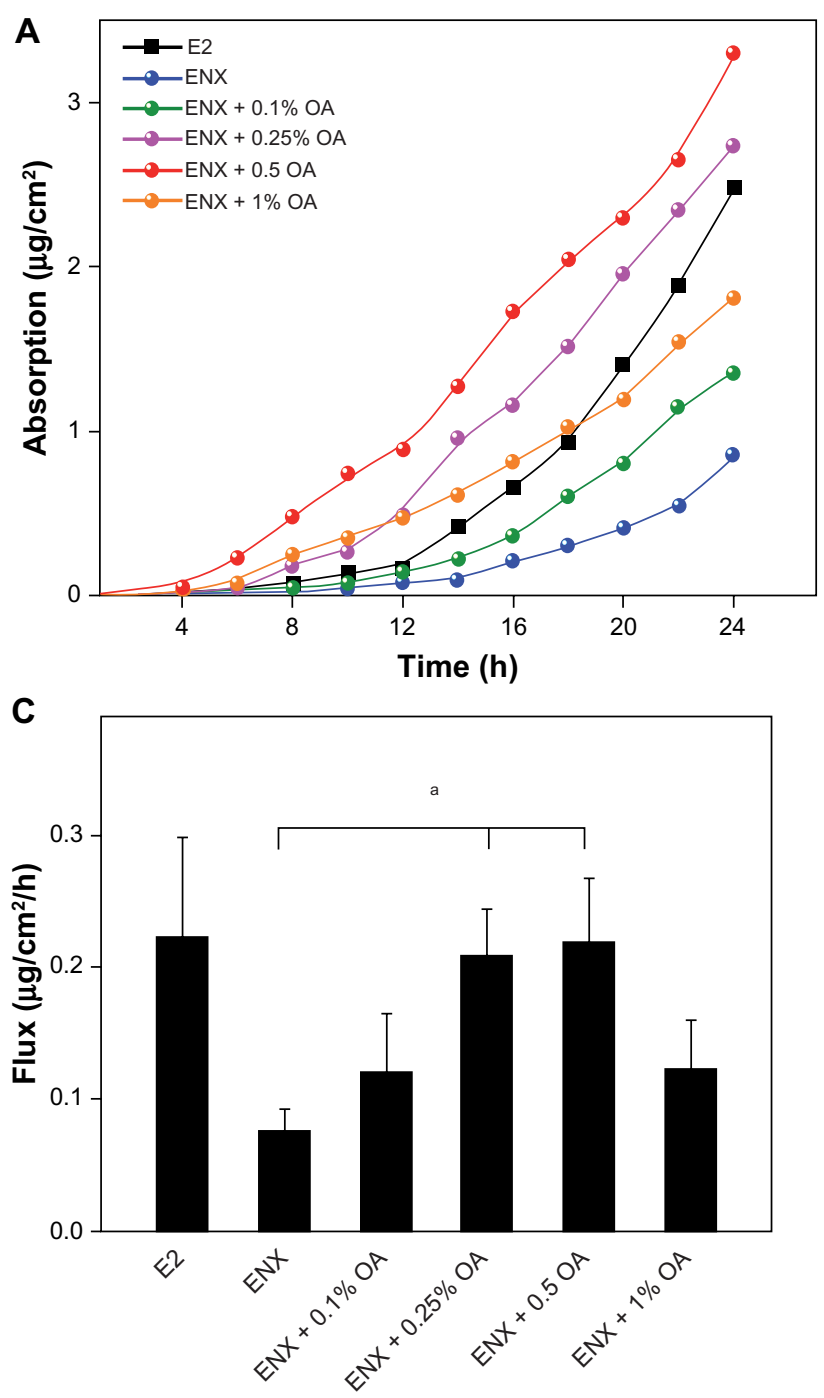

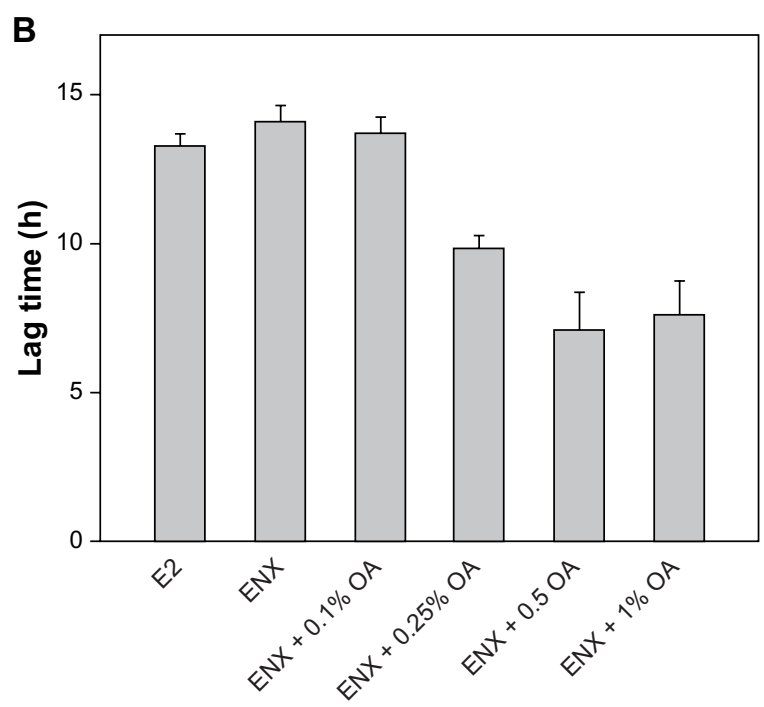

D

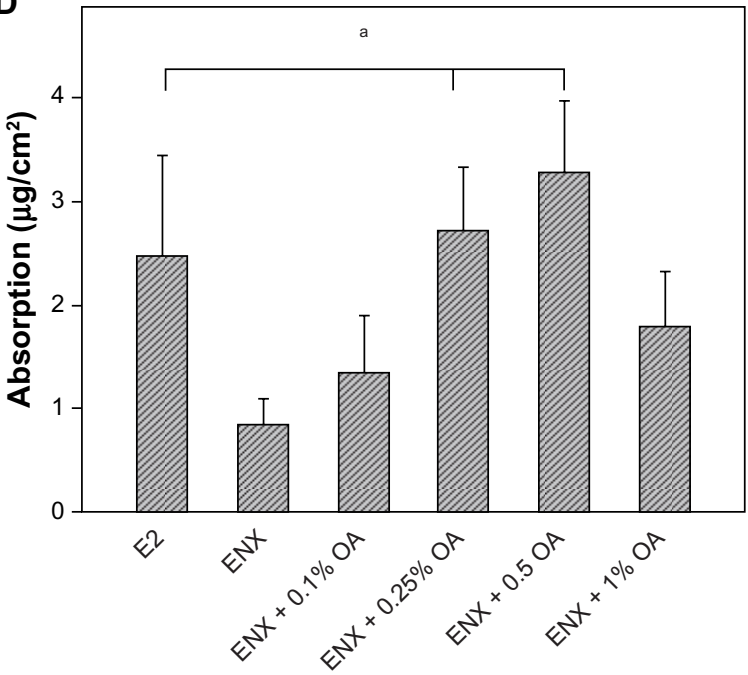

Figure 3 Permeation parameters of ENX compared with E2. The applied dose of the compounds was $78.9\left(\mu \mathrm{g} / \mathrm{cm}^{2}\right)$. The skin samples from three subjects were used and each treatment condition was tested in duplicate on the skin samples from a subject in each experiment. (A) permeation profile, (B) lag time, $(\mathbf{C})$ flux $\left(\mu g / \mathrm{cm}^{2} / \mathrm{h}\right)$, and (D) absorption at $24 \mathrm{~h}(\mu \mathrm{g} / \mathrm{cm}$ were expressed as the mean $\pm \mathrm{SEM}, \mathrm{n}=5-6$. The P-values were determined using the Wilcoxon rank sum test.

Note: a $P<0.05$.

Abbreviations: ENX, endoxifen; E2, estradiol; OA, oleic acid; SEM, standard error of the mean.

agree with previous findings using hairless rat skin, which showed that the co-solvent system of OA-ethanol-water efficiently increased skin permeation of both lipophilic and hydrophilic drugs. ${ }^{15}$

The effect of OA as a permeation enhancer was markedly divergent between the EpiDerm and human STS; the general permeation-enhancing effect of $\mathrm{OA}$ was not only absent in the EpiDerm model, but also the permeation was significantly reduced. The EpiDerm model does not have the papillary dermal layer of normal human STS, and the thickness of the stratum corneum was almost $50 \%<$ human STS used in our experiments. Thus, the reason for the inhibition of permeation by OA in the EpiDerm may be related to its lipid characteristics and thin, imperfectly developed stratum corneum, derived from cultured human keratinocytes, so that the favorable effects of OA on the partitioning of compounds through the skin are not observed. This suggests that the reconstituted epidermis is not a suitable model for the testing of permeation enhancers, such as $\mathrm{OA}$, that depend on partitioning with lipids in the stratum corneum.

The permeation enhancing effect of OA was assessed at lower concentrations $(0.1 \%-1 \%)$ to find an optimal concentration of OA for ENX in $60 \%$ ethanolic solution, with $\mathrm{E} 2$ as a reference transdermal compound, to determine whether the permeation of ENX with OA can be improved to a level consistent with effective transdermal delivery. The results show that the addition of $0.25 \%-0.5 \%$ OA 
A

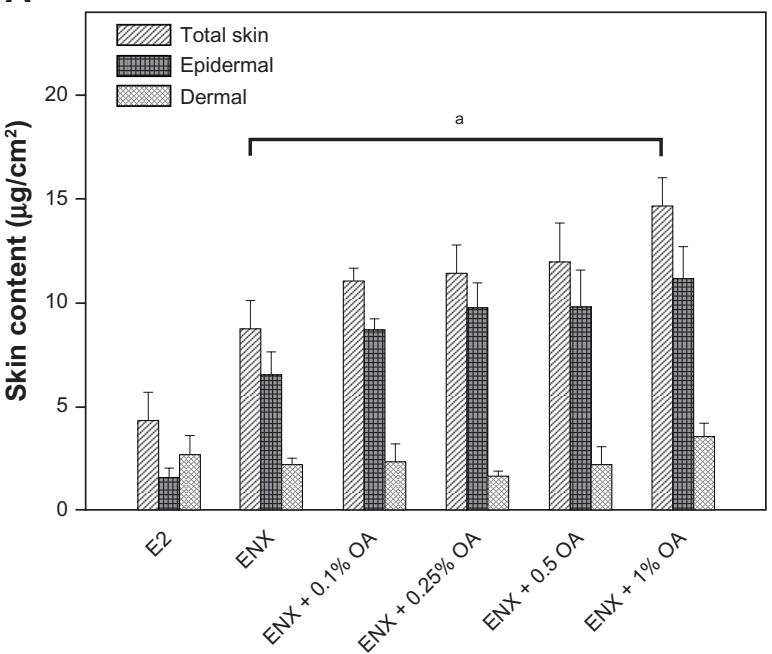

B

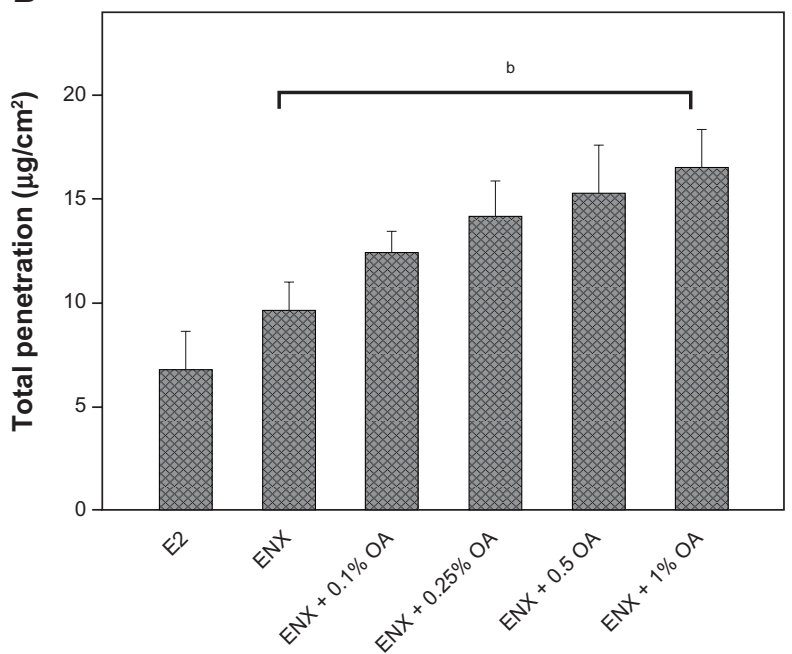

Figure 4 Skin content and total penetration of ENX compared with E2. The applied dose of the compounds was $78.9\left(\mu \mathrm{g} / \mathrm{cm}^{2}\right)$. The skin samples from three subjects were used and each treatment condition was tested in duplicate on the skin samples from each subject in each experiment. (A) Skin content ( $\left.\mu g / \mathrm{cm}^{2}\right)$ of the compounds was measured separately from epidermis and dermis and was combined as total skin content after $24 \mathrm{~h}$. (B) TP of the compounds was determined as the sum of absorption and total skin contents after $24 \mathrm{~h}$. All measurements were expressed as the mean $\pm \mathrm{SEM}, \mathrm{n}=5-6$. The P-values were determined using the Wilcoxon rank sum test. Notes: $a p=0.045 ;$ bp $=0.029$.

Abbreviations: ENX, endoxifen; E2, estradiol; OA, oleic acid; SEM, standard error of the mean; TP, total penetration.

maximizes the flux of ENX over 24 hours and higher concentrations of $\mathrm{OA}$ do not result in further improvement. Overall, $0.25 \%-0.5 \%$ OA seems to be the optimal concentration for $60 \%$ ethanolic vehicle system as a fast and efficient transdermal delivery of ENX. Furthermore, although ENX alone permeates human skin slower than E2, the addition of OA not only improves the absorption of ENX to a level similar to that of E2, but also significantly increases skin deposition of ENX. Together, these results suggest that ENX is an excellent candidate for transdermal delivery.

The direct delivery of active metabolites to the breast through its skin envelope averts first-pass metabolism in the liver, potentially avoiding changes in the clotting cascade that lead to the prothrombotic effects of TAM and raloxifene. ${ }^{2,21,22}$ Since risk of thromboembolism is a major concern not only with TAM use, but also with all selective estrogen-receptor modulators (SERMs) tested clinically to date, its avoidance would be a significant advantage for women considering SERM therapy for breast cancer prevention and for treatment of DCIS. Additionally, the very low plasma concentrations of following transdermal application of 4-OHT observed in the studies conducted so $\mathrm{far}^{7,8,11}$ suggest that uterine toxicity and hot flashes would be reduced by the transdermal delivery of active TAM metabolites to the breast. Furthermore, limitations on the bioavailability of active metabolites that are caused by polymorphisms in TAM metabolizing genes ${ }^{3,4}$ would be overcome by this approach.

Finally, the issue of whether transdermal delivery to the breast is a local or a systemic treatment deserves consideration. The preliminary studies conducted by Mauvais-Jarvis and colleagues in the 1980s and 1990s showed that 4-OHT applied through the skin of the breast concentrates in the breast at $10 \times$ higher levels than when it is applied to the arm or shoulder. ${ }^{7,8}$ The investigators attributed this accumulation to the binding of 4-OHT to ER present in breast tumors and breast epithelium. In fact, ER $\alpha$ expression in nonmalignant breast tissue is very low but ER $\beta$ is high and may account for at least some of the localization in the breast. However, receptor binding alone is insufficient to explain 4-OHT retention in the breast. ${ }^{23,24}$ A more plausible explanation relates to the embryological origin of the breast as a skin appendage (ie, a modified sweat or apocrine gland). Studies of the embryology of the breast suggest that the breast gland (parenchyma) and its skin envelope are a single unit with a well-developed internal lymphatic (and venous) circulation. ${ }^{25}$ These embryological studies are supported by the fact that the skin and parenchyma of the breast drain to the same sentinel nodes. ${ }^{26,27}$ Therefore, other drugs applied to the skin of the breast should concentrate in the parenchyma to a greater degree than can be expected based on systemic absorption and delivery through the circulation, and the model of transdermal local pharmacotherapy 
for breast cancer prevention and for DCIS therapy should be extendable to a variety of agents as long as they show sufficient dermal permeation.

It is too early to draw any conclusion for potential clinical use since it remains uncertain whether a level of ENX in the breast by transdermal delivery is equivalent to the clinical efficacy of oral TAM. To address this, the authors have initiated an in vivo preclinical study to assess mammarygland and systemic distribution of ENX by transdermal delivery, and to evaluate the in vivo therapeutic efficacy of ENX, compared with standard doses of oral TAM in the hairless rat model. ${ }^{28}$ These studies will guide the development of a clinical study to evaluate the efficacy of this approach for prevention of ER positive breast cancer in the near future.

\section{Conclusion}

These results demonstrate that the addition of $\mathrm{OA}$ improves absorption of ENX through human skin in vitro to the same range as that seen for E2, providing strong justification for the development of ENX for local transdermal delivery to the breast. The data raise questions about the suitability of the EpiDerm model for the evaluation of skin permeation enhancement and suggest that the permeation dynamics of human skin differ substantially from those of reconstituted human epidermis.

\section{Acknowledgments}

The authors thank Dr Russell O Potts, Russ Potts Consulting, LLC, San Francisco, CA, for valuable discussions regarding setup of in vitro human skin permeation experiment and permeation enhancers. The present study was supported by grants from Lynn Sage Breast Cancer Foundation and the Susan G Komen Foundation.

\section{Disclosure}

The authors report no conflicts of interest in relation to this work.

\section{References}

1. Jordan VC. Chemoprevention of breast cancer with selective oestrogenreceptor modulators. Nat Rev Cancer. 2007;7(1):46-53.

2. Cuzick J, Powles T, Veronesi U, et al. Overview of the main outcomes in breast-cancer prevention trials. Lancet. 2003;361(9354):296-300.

3. Goetz MP, Rae JM, Suman VJ, et al. Pharmacogenetics of tamoxifen biotransformation is associated with clinical outcomes of efficacy and hot flashes. J Clin Oncol. 2005;23(36):9312-9318.

4. Goetz MP, Knox SK, Suman VJ, et al. The impact of cytochrome P450 2D6 metabolism in women receiving adjuvant tamoxifen. Breast Cancer Res Treat. 2007;101(1):113-121.

5. Wu X, Hawse JR, Subramaniam M, Goetz MP, Ingle JN, Spelsberg TC. The tamoxifen metabolite, endoxifen, is a potent antiestrogen that targets estrogen receptor alpha for degradation in breast cancer cells. Cancer Res. 2009;69(5):1722-1727.
6. Fisher B, Costantino JP, Wickerham DL, et al. Tamoxifen for prevention of breast cancer: report of the National Surgical Adjuvant Breast and Bowel Project P-1 Study. J Natl Cancer Inst. 1998;90(18): 1371-1388.

7. Mauvais-Javis P, Baudot N, Castaigne D, Banzet P, Kuttenn F. trans4-Hydroxytamoxifen concentration and metabolism after local percutaneous administration to human breast. Cancer Res. 1986;46(3): $1521-1525$.

8. Pujol H, Girault J, Rouanet P, et al. Phase I study of percutaneous 4-hydroxy-tamoxifen with analyses of 4-hydroxy-tamoxifen concentrations in breast cancer and normal breast tissue. Cancer Chemother Pharmacol. 1995;36(6):493-498.

9. Rouanet P, Linares-Cruz G, Dravet F, et al. Neoadjuvant percutaneous 4-hydroxytamoxifen decreases breast tumoral cell proliferation: a prospective controlled randomized study comparing three doses of 4-hydroxytamoxifen gel to oral tamoxifen. J Clin Oncol. 2005;23(13): 2980-2987.

10. Bronaugh RL, Stewart RF. Methods for in vitro percutaneous absorption studies. VI: preparation of the barrier layer. J Pharm Sci. 1986;75(5): 487-491.

11. Mansel R, Goyal A, Nestour EL, Masini-Eteve V, O'Connell K. A phase II trial of Afimoxifene (4-hydroxytamoxifen gel) for cyclical mastalgia in premenopausal women. Breast Cancer Res Treat. 2007; 106(3):389-397.

12. Lim YC, Desta Z, Flockhart DA, Skaar TC. Endoxifen (4-hydroxy$\mathrm{N}$-desmethyl-tamoxifen) has anti-estrogenic effects in breast cancer cells with potency similar to 4-hydroxy-tamoxifen. Cancer Chemother Pharmacol. 2005;55(5):471-478.

13. Lim YC, Li L, Desta Z, et al. Endoxifen, a secondary metabolite of tamoxifen, and 4-OH-tamoxifen induce similar changes in global gene expression patterns in MCF-7 breast cancer cells. J Pharmacol Exp Ther. 2006;318(2):503-512.

14. Williams AC, Barry BW. Penetration enhancers. Adv Drug Deliv Rev. 2004;56(5):603-618.

15. Kim DD, Kim JL, Chien YW. Mutual hairless rat skin permeationenhancing effect of ethanol/water system and oleic acid. J Pharm Sci. 1996;85(11):1191-1195.

16. Kim MJ, Doh HJ, Choi MK, et al. Skin permeation enhancement of diclofenac by fatty acids. Drug Deliv. 2008;15(6):373-379.

17. Goodman M, Barry BW. Action of penetration enhancers on human skin as assessed by the permeation of model drugs 5-fluorouracil and estradiol. I. Infinite dose technique. J Invest Dermatol. 1988;91(4):323-327.

18. Fang JY, Hwang TL, Leu YL. Effect of enhancers and retarders on percutaneous absorption of flurbiprofen from hydrogels. Int J Pharm. 2003;250(2):313-325.

19. Yu B, Dong CY, So PT, Blankschtein D, Langer R. In vitro visualization and quantification of oleic acid induced changes in transdermal transport using two-photon fluorescence microscopy. J Invest Dermatol. 2001;117(1):16-25.

20. Ogiso T, Paku T, Iwaki M, Tanino T. Percutaneous penetration of fluorescein isothiocyanate-dextrans and the mechanism for enhancement effect of enhancers on the intercellular penetration. Biol Pharm Bull. 1995; 18(11):1566-1571.

21. Cosman F, Baz-Hecht M, Cushman M, et al. Short-term effects of estrogen, tamoxifen and raloxifene on hemostasis: a randomizedcontrolled study and review of the literature. Thromb Res. 2005;116(1): $1-13$.

22. Cuzick J, Forbes J, Edwards R, et al. First results from the International Breast Cancer Intervention Study (IBIS-I): a randomised prevention trial. Lancet. 2002;360(9336):817-824.

23. Khan SA, Rogers MA, Khurana KK, Meguid MM, Numann PJ. Estrogen receptor expression in benign breast epithelium and breast cancer risk [see comments]. J Natl Cancer Inst. 1998;90(1):37-42.

24. Ricketts D, Turnbull L, Ryall G, et al. Estrogen and progesterone receptors in the normal female breast. Cancer Res. 1991;51: $1817-1822$. 
25. Ackerman AB, Kessler G, Gyorfi T, Tsou HC, Gottlieb GJ. Contrary view: the breast is not an organ per se, but a distinctive region of skin and subcutaneous tissue. Am J Dermatopathol. 2007;29(2): 211-218.

26. Povoski SP, Olsen JO, Young DC, et al. Prospective randomized trial comparing intradermal, intraparenchymal, and subareolar injection routes for sentinel lymph node mapping and biopsy in breast cancer. Ann Surg Oncol. 2006;13(2):10-11.
27. Klimberg VS, Rubio IT, Henry R, Cowan C, Colvert M, Korourian S. Subareolar versus peritumoral injection for location of the sentinel lymph node. Ann Surg. 1999;229(6):860-864.

28. Lien EA, Solheim E, Ueland PM. Distribution of tamoxifen and its metabolites in rat and human tissues during steady-state treatment. Cancer Res. 1991;51(18):4837-4844.

\section{Publish your work in this journal}

Breast Cancer: Targets and Therapy is an international, peerreviewed open access journal focusing on breast cancer research, identification of therapeutic targets and the optimal use of preventative and integrated treatment interventions to achieve improved outcomes, enhanced survival and quality of life for the cancer patient.
View the full aims and scopes of this journal here. The manuscript management system is completely online and includes a very quick and fair peer-review system, which is all easy to use. Visit http:// www.dovepress.com/testimonials.php to read real quotes from published authors.

Submit your manuscript here: http://www.dovepress.com/breast-cancer---targets-and-therapy-journal 